\section{THE SOUTH AFRICAN MEDAL OF THE BRITISH ASSOCIATION.}

WHEN the members of the British Association were in South Africa last August and September, it occurred to someone of the party that it would be well to commemorate our visit by founding a medal for South Af 1 ican students. I am sorry that I cannot remèmber to whom the credit of this admirable suggestion is due, but the officers at once adopted it with enthusiasm. Papers explaining the proposal were first circulated through the special trains on our way from Durban to Johannesburg, and a substantial sum was promised in a very short time. The proposal was subsequently laid before those who did not happen to be travelling in the special trains, and ultimately before all the members of the British Association.

On our return to England, a meeting of the subscribers was summoned, and a committee was appointed to consider the manner in which the fund should be applied. It was resolved that the South African Association for the Advancement of Science should be a,ked to accept the trusteeship and adminis-

balance will come to about $500 l$. It is clear that this balance ought to be returned to South Africa in some way, and a resolution has been passed by the council of the association that the unexpended balance shall be devoted to the augmentation of the medal fund. The expenses attendant on the design of the medal have amounted to about rool., and it is hoped that more than $1200 l$. will remain for transmission to South Africa. As a higher rate of interest on safe investments is obtainable there than here, a substantial annual sum will be provided in aid of research.

The cordiality of our reception in South Africa surpassed all that could possibly have been foreseen, and we in England are glad to be able to establish this small foundation as a memorial of the most remarkable of the many annual meetings of the British Association. G. H. Darwin.

THE EARTHQUAKE IN SOUTH WALES.

THE earthquake which occurred in South Wales on 1 June 27 at about 9.45 a.m. ranks among the strongest shocks of which we have had any experience in this country. It was felt over the whole of Wales,

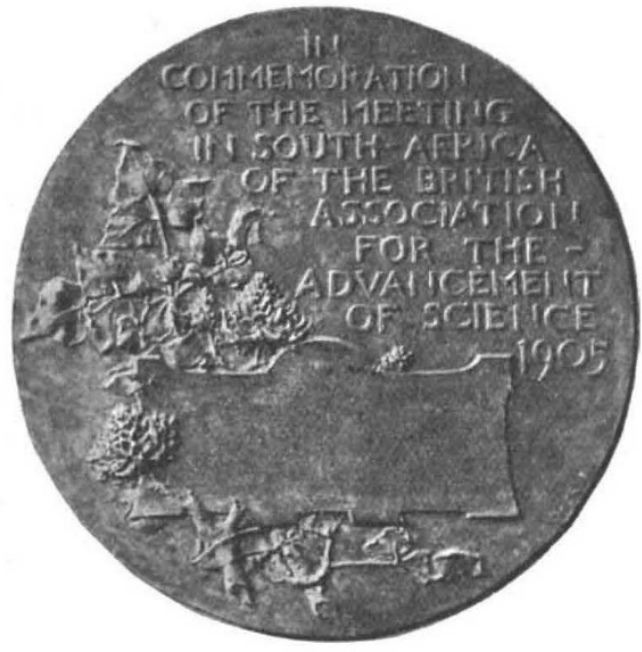

Mr. Frank Bowcher's Designs for the South African Medal of the British Association

tration of the fund, and to undertake the annual award of the medal which was to be struck.

The income of the fund was to be in aid of scientific research among South African students, and it was thought that the medal would commemorate appropriately the fact that the recipient of the award was of such promise as to have been deemed worthy of the confidence placed in him.

The South African Association has cordially accepted the duties in question, and a medal, shown in the illustration, and to be struck in bronze, has been designed by Mr. Frank Bowcher.

The total sum subscribed by the members of the British Association amounts to $859 l$., but the fund will receive a further substantial augmentation, as I shall now explain.

Before the meeting of last year, the several South African colonies subscribed a large sum in aid of the expenses of the members intending to come out to South Africa, and this sum was supplemented, although on a less liberal scale, by a subscription in England. The total of this special South African fund was a little more than goool. It is expected that, when all the accounts are settled, the unexpended and throughout the greater part of the west and southwest of England. Judging from the accounts which I have already received, the disturbed area must extend some distance to the north of Liverpool; towards the east it includes Northampton and Maidenhead, and approaches to within about twenty miles of London, while the southern boundary lies in the English Channel to the south of Dorset, Devon, and Cornwall. I have not yet obtained any observations from Ireland, but there can be little doubt that the shock was sensible over most of the counties of Wicklow and Wexford. A first rough estimate makes the disturbed area nearly circular in form, about 280 miles in diameter, and about 60,000 square miles in area.

The shock, which affected a region greater than the combined areas of England and Wales, was naturally of considerable strength within the central district. It is too early to make any estimate of the total damage to buildings, but the first reports show that a very large number of chimneys were thrown down, especially in Swansea, where the number is said to amount to several hundred. From Kidwelly on the west to beyond Neath on the east, and from Glanamman on the north to beyond Swansea on the 